\title{
The status of medication literacy and associated factors of hypertensive patients in China: a cross-sectional study
}

\author{
Guiyue Ma ${ }^{1,2} \cdot$ Aijing Luo $^{3} \cdot$ Zhiying Shen ${ }^{1} \cdot$ Yinglong Duan $^{1} \cdot$ Shuangjiao Shi ${ }^{1,2} \cdot$ Zhuqing Zhong $^{1,2,3}$
}

Received: 18 June 2019 / Accepted: 28 August 2019 / Published online: 24 October 2019

(c) The Author(s) 2019

\begin{abstract}
The adverse consequence of low medication literacy is a major problem that threatens patients' health. The number of people with hypertension is increasing in China. We described the current situation of medication literacy of patients with hypertension in China and its related influencing factor. We conducted a cross-sectional study, which contains 590 hypertensive patients. Stratified sampling was adopted according to the hospital level in China. To determine the factors related to medication literacy, multiple linear regression analysis was used to determine associations between medication literacy of hypertensive patients and other factors. Among 590 respondents, results showed that they have poor medication literacy. Multiple linear regression analysis showed that level of education, annual income, occupation status, and type of medical insurance were significantly associated with medication literacy level of hypertensive patients. In addition, our study also demonstrates that we can identify the medication literacy level of hypertensive patients using the Chinese version Medication Literacy Scale for Hypertensive Patients. High medication literacy is an important factor for hypertensive patients to improve medication adherence, so as to better control blood pressure. We should pay attention to the improvement of medication literacy and take corresponding measures.
\end{abstract}

Keywords Medication literacy $\cdot$ Hypertensive patients $\cdot$ Blood pressure control

Guiyue Ma and Aijing Luo are contributed equally to this paper and are the first authors.

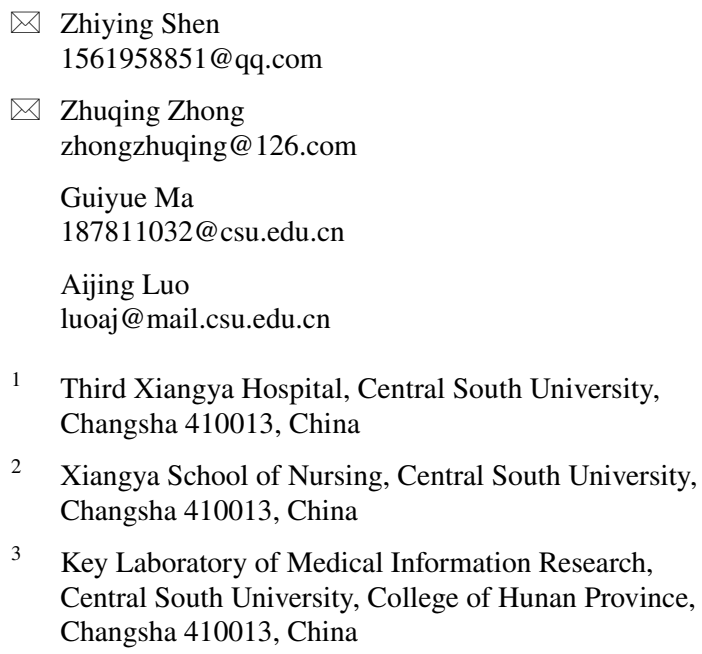

2 Xiangya School of Nursing, Central South University, Changsha 410013, China

3 Key Laboratory of Medical Information Research, Central South University, College of Hunan Province, Changsha 410013, China

\section{Introduction}

In China, hypertension has become an increasingly important topic, both for the public and the government [1]. Hypertension has been a great burden of disease. According to Report of cardiovascular diseases in China 2017 [2], there are currently 290 million people suffering from cardiovascular diseases, among whom 270 million are suffering from hypertension, accounting for $1 / 5$ of the total number of people with hypertension in the world. Poor self-management and control of hypertension will lead to a variety of serious cardiovascular events, and its low awareness rate, low treatment rate, and low control rate greatly accelerate the occurrence and development of cardiovascular disease, causing great obstacles to the management and control of cardiovascular disease [3]. According to the report of the World Health Organization, $45 \%$ of the total deaths in China were caused by cardiovascular diseases in 2014 [4], and 50\% of the cerebral apoplexy could be attributed to hypertension [5]. Besides, in the Summary of 2016 China cardiovascular disease report released in June 2017, the prevalence of people with hypertension over 18 years old is $25.2 \%$ in China 
[1]. It can be seen that Chinese hypertension patients tend to be younger, which further burdens the country and patients.

There are many treatments for high blood pressure, but top of the list is medication. The primary treatment for hypertension is still dominated by drug therapy, which plays an important role in the control of hypertension. Selfmedication safety of patients with hypertension has always been the focus of researchers in the field of medicine and public health care. Because drug therapy is one of the most effective preventive and therapeutic measures for patients with hypertension [6]. Therefore, countries all over the world spend a lot of money on medicine every year [7, 8], especially in the treatment of hypertension [9]. In China, people spend more and more on medical care, which causes an increasing burden on people [10]. Studies show that $90 \%$ of hypertension patients can control their blood pressure at a safe level by taking drugs. However, the control rate of hypertension is still low, about $31 \%$ in developed countries and only $8.1 \%$ in China [11]. The reason is that patients' poor medication adherence leads to poor blood pressure control [12]. Nonadherence to medication is the major cause of poor blood pressure control, leading to cardiovascular disease and stroke $[13,14]$. Even in patients with known complications such as myocardial infarction, poor medication adherence is also normal. Lau et al. [15] found in their study that less than half of hypertensive patients who took blood pressure lowering drugs for 1 year could still take the drugs consistently. Approximately 50\% of CVD patients have poor adherence to their prescribed medications, which has adverse effects on morbidity, mortality, and recurrent cardiac complications, as well as higher costs [16, 17]. Many studies have shown that self-medication of antihypertensive drugs is poor in patients with hypertension, including poor adherence to antihypertensive drugs and medication errors [18]. Therefore, patients' long-term regular use of antihypertensive drugs is an important way to stabilize blood pressure, control the disease and prevent serious complications. However, patients' medication literacy is often low. As a result, the key to chronic disease control is the ability of patients to manage medications [19].

Medication literacy refers to the ability of an individual to self-medicate in a safe and appropriate way on the basis of obtaining, comprehending and communicating the information about the medications and correctly evaluating it, regardless of the manner in which the content is provided (e.g., written, verbal, and visual) [20]. The efficacy of drug therapy in patients with hypertension depends on their understanding of drug information and ability to obtain relevant support, which is conducive to patients' safe and rational self-medication. Therefore, high medication literacy is essential for successful treatment of patients with hypertension [21].
Currently, there is a lack of relevant medication literacy assessment tools for hypertensive patients in mainland China and there is also a lack of relevant cross-sectional studies on medication literacy of patients with hypertension, which is the gap we found. Therefore, on the basis of the pre-developed evaluation scale of medication literacy of hypertension patients, we designed Chinese version Medication Literacy Scale for Hypertensive Patients (C-MLSHP) to measure the medication literacy of hypertensive patients. In addition, the medication literacy of 540 cases of hypertensive patients in Changsha was investigated to analyze the relevant factors. This study aims to investigate the status of medication literacy in hypertensive patients in China and the influencing factors of medication literacy, so as to provide references for further improving the safe and reasonable self-medication of hypertensive patients.

\section{Methods}

\section{Design and setting}

This study was a cross-sectional survey conducted from August to December, 2016 with the purpose of understanding the factors related to medication literacy in patients with hypertension to improve the ability of safe and reasonable self-medication and blood pressure management. Based on the classification method of hospital level in China and the number of those hospitals of different levels, where patients with hypertension can be treated. Using the method of stratified sampling, 3 hospitals were selected from 15 tertiary hospitals and 2 from 11 secondary hospitals in Changsha City, Hunan Province. In addition, 3 community health service institutions were randomly selected from 15 communities in YueLu District of Changsha City, which sampling proportion is $20 \%$ individually.

\section{Study sample}

Hypertensive patients who meet the inclusion criteria were participated to our study.

Inclusion criteria: (1) has been diagnosed as hypertension according to 2016 Revised Edition of Guideline to Hypertension Therapy in China; (2) over 18 years old; (3) time for antihypertensive medication over 2 weeks; (4) with clear consciousness and normal communication skills; and (5) agree to participate in this study and signed the informed consent. Exclusion criteria: (1) with severe associated disease of heart, brain, kidney and liver, and so on and (2) with mental illness. 


\section{Measures}

\section{General information}

Data collection was completed by four full-time graduate students who were trained before data collection to ensure the quality and scientific nature of the data. The members of the study group, after obtaining the permission of the relevant officers of the various investigation centers, selected the subjects that met the inclusion and exclusion criteria; the study population were informed the purpose and significance of the study and signed the informed consent. Participants were asked to complete a self-made general demographic questionnaire regarding their age, gender, education, income by year, marital status, occupation, location, type of medical insurance, history of hypertension, family history of hypertension, complication of hypertension, the number of antihypertensive drugs being taken, and the number of people who live together. The questionnaires were required to be filled out and collected on the spot, and the completion of the questionnaire was been checked, reason was been asked if there was an omitted item in the questionnaire, then the omission had to been filled as complete as possible by participants.

\section{Chinese version Medication Literacy Scale for Hypertensive Patients (C-MLSHP)}

We designed the Chinese version Medication Literacy Scale for Hypertensive Patients (C-MLSHP) to measure the medication literacy of hypertensive patients, which was based on four dimensions: medication knowledge literacy, skill literacy, attitude literacy, and practice literacy, a total of 37 items. The contents include nine items for medication knowledge literacy, including three factors of self-medication knowledge, knowledge of hypertension, knowledge of hypertension therapy; eight items for attitude literacy, including two factors of attitude to self-medication and disease of hypertension; seven items for skill literacy, including two factors of reading, comprehension skill and calculating skill; 13 items for practice literacy, including four factors of compliance behavior, behavior of medication decision, behavior of blood pressure monitoring, medication information-seeking, and disseminating behavior. The Cronbach's $\alpha$ coefficient of the scale is 0.849 , and the Cronbach's $\alpha$ coefficient of each subscale is between 0.744 and 0.783 . The split-half reliability of the whole scale is 0.893 and the split-half reliability of subscales are from 0.793 to 0.872 ; The test-retest reliability of the whole scale is 0.968 and the test-retest reliability of subscales are from 0.880 to 0.959 ; I-CVI was 0.833-1.000, S-CVI was 0.968 .

The total scores range from 0 to 37 , of which the correct answer of each dimension of knowledge and skill was 1 , and the wrong answer was 0 . In the dimension of attitude and practice, the Likert-5 scores were 1.0, 0.75, 0.5, 0.25, 0 . Among them, there are five reverse items in attitude dimension and one reverse item in practice dimension, and the score is opposite. In general, the higher the score, the higher the medication literacy.

\section{Data analysis}

All the data in this study were recorded by two persons. Excle2016 was used to record and store the data. We examined the collected data, then collate and encode it. Means and standard deviations were used to describe quantitative variables, frequencies and percentages were used to describe categorical variables. $T$ test, LSD $t$ test, and multiple linear regression analysis were used for inferential statistics. Statistical analysis was performed using SPSS version 22 . The criterion of significance is $\alpha=0.05$, which makes sense if $P<0.05$.

\section{Results}

\section{General information}

Totally, 590 hypertensive patients were surveyed in this study. 590 questionnaires were sent out and 590 were collected and response rate was $100 \%$. Nevertheless, there were 540 validated questionnaires after checking, so the validated rate was $91.7 \%$. Approximately $11.5 \%$ of participants had completed junior college, $18.7 \%$ of participants earned more than 100,000 a year, $75.6 \%$ of participants occupied, $41.9 \%$ of participants have medical insurance for urban workers. Other general information about participants are shown in Table 1.

\section{Scores of each dimension of medication literacy in hypertensive patients}

The medication literacy of hypertensive patients has four dimensions, and the results show that hypertensive patients have the highest score in knowledge literacy and the lowest score in skill literacy, as shown in Table 2.

\section{Analysis on influencing factors of medication literacy of hypertensive patients}

\section{Scores on medication literacy assessment scale of hypertensive patients with different characteristics}

The score and characteristics of each dimension of the medication literacy assessment scale of hypertensive patients are 
Table 1 Demographics of hypertensive patients $(n=540)$

\begin{tabular}{|c|c|c|c|}
\hline & Items & $n$ & $\%$ \\
\hline \multirow[t]{3}{*}{ Age } & $18-44$ & 58 & 10.70 \\
\hline & $45-59$ & 172 & 31.90 \\
\hline & $\geq 60$ & 310 & 57.40 \\
\hline \multirow[t]{2}{*}{ Gender } & Male & 298 & 55.20 \\
\hline & Female & 242 & 44.80 \\
\hline \multirow[t]{5}{*}{ Education level } & Primary or below & 149 & 27.60 \\
\hline & Junior middle school & 145 & 26.90 \\
\hline & High school or polytechnic school & 101 & 18.70 \\
\hline & Junior college & 62 & 11.50 \\
\hline & Bachelor degree or above & 83 & 15.40 \\
\hline \multirow[t]{5}{*}{ Annual Income } & $<10,000 /$ year & 94 & 17.40 \\
\hline & $10,000-29,000 /$ year & 106 & 19.63 \\
\hline & $30,000-49,000 /$ year & 146 & 27.04 \\
\hline & $50,000-99,000 /$ year & 93 & 17.20 \\
\hline & $\geq 100,000 /$ year & 101 & 18.70 \\
\hline \multirow[t]{3}{*}{ Marital status } & Married & 479 & 88.70 \\
\hline & Unmarried & 10 & 1.90 \\
\hline & Divorced or widowed & 51 & 9.50 \\
\hline \multirow[t]{3}{*}{ Occupation } & Occupied & 374 & 75.60 \\
\hline & Retired & 128 & 23.70 \\
\hline & Jobless & 38 & 7.00 \\
\hline \multirow[t]{2}{*}{ Habitation } & Urban & 310 & 57.40 \\
\hline & Country & 230 & 42.60 \\
\hline \multirow[t]{5}{*}{ Type of medical insurance } & New rural cooperative medical insurance & 206 & 38.10 \\
\hline & Medical insurance for urban workers & 226 & 41.90 \\
\hline & Medical insurance for urban residents & 86 & 15.90 \\
\hline & Other & 15 & 2.80 \\
\hline & Without medical insurance & 7 & 1.30 \\
\hline \multirow[t]{4}{*}{ A history of hypertension } & $<3$ years & 101 & 18.70 \\
\hline & $3-4$ years & 90 & 16.70 \\
\hline & $5-9$ years & 144 & 26.70 \\
\hline & $\geq 10$ years & 205 & 38.00 \\
\hline \multirow[t]{2}{*}{ Family history of hypertension } & Yes & 348 & 64.40 \\
\hline & No & 192 & 35.60 \\
\hline \multirow[t]{3}{*}{ Hypertension complication } & Yes & 146 & 27.00 \\
\hline & No & 394 & 73.00 \\
\hline & One or none & 333 & 61.70 \\
\hline \multirow{3}{*}{$\begin{array}{l}\text { The number of antihypertensive medica- } \\
\text { tions being taken }\end{array}$} & $2-3$ kinds & 185 & 34.30 \\
\hline & 4 kinds or above & 22 & 4.10 \\
\hline & One or none & 24 & 4.40 \\
\hline \multirow[t]{3}{*}{ The number of people who live together } & $2-4$ & 346 & 64.10 \\
\hline & $5-7$ & 142 & 26.30 \\
\hline & 8 or above & 28 & 5.20 \\
\hline
\end{tabular}

different, and the results of t test and LSD $t$ test in each item are shown in Table 3.

\section{Multiple linear regression analysis on influencing factors of medication literacy of hypertensive patients}

In this study, the independent variables are age, gender, education level, annual income, marital status, occupation, habitation, type of medical insurance, a history of hypertension, 
Table 2 Scores in each dimension of medication literacy of hypertensive patients

\begin{tabular}{lcclc}
\hline Dimensions & Range of score & Overall average score & Average score of items & sequence \\
\hline Knowledge literacy & $0.00-9.00$ & $6.28 \pm 2.21$ & $0.70 \pm 0.25$ & 1 \\
Attitude literacy & $2.00-8.00$ & $5.36 \pm 1.20$ & $0.67 \pm 0.15$ & 2 \\
Skill literacy & $0.00-7.00$ & $4.51 \pm 2.15$ & $0.64 \pm 0.31$ & 4 \\
Practice literacy & $1.00-12.75$ & $8.46 \pm 1.95$ & $0.65 \pm 0.15$ & 3 \\
Medication literacy & $11.50-35.5$ & $24.61 \pm 5.13$ & $0.67 \pm 0.14$ & \\
\hline
\end{tabular}

family history of hypertension, hypertension complication, the number of antihypertensive medications being taken, the number of people who live together. The dependent variables are score of medication literacy of hypertensive patients and score of each dimension of medication literacy (specific assignment for variables are in Table 4). Multiple linear regression analysis was used. The results show that the education level, annual income, occupation, medical insurance type are the influencing factors on medication literacy of hypertensive patients, which are shown on Table 5.

\section{Discussion}

\section{The level of medication literacy of patients with hypertension needs to be improved}

There are no studies that investigate the influencing factors related to medication literacy of hypertension. Furthermore, failure to adhere to medication is a preventable cause of treatment failure [6]. The goal of our study is to describe the current situation of medication literacy of patients with hypertension in China and its related influencing factor. The results showed that they scored totally $(24.61 \pm 5.13)$ in medication literacy, of which each dimension was scored an average of $(0.67 \pm 0.14)$. Results show that the medication literacy of patients with hypertension is not high. Therefore, it is particularly necessary to explore the influencing factors of medication literacy in hypertensive patients.

Furthermore, from the scoring results of each dimension of medication literacy, we can see that the average score of knowledge literacy is the highest, followed by the scores of attitude, practice and skill literacy. It is concluded that patients with hypertension have a better understanding of the disease of hypertension and knowledge of antihypertensive drugs than skills, attitudes, and practices of self-medication. Moreover, the poor quality of self-medication practice in hypertensive patients indicates that they cannot put their medication knowledge into safe and reasonable self-medication practice. The study also proved that we can measure the medication literacy level of hypertensive patients using the Chinese version Medication Literacy Scale for Hypertensive Patients (C-MLSHP).

\section{Influencing factors of level of medication literacy of hypertensive patients}

\section{Education level influencing on level of medication literacy of hypertensive patients}

The results showed that the differences of medication literacy in hypertensive patients with different levels of education were mainly manifested in the two dimensions of knowledge and skill literacy, which was similar to Newman et al. [22]. However, Lin et al. [23] found that knowledge related to disease was irrelevant to medication adherence. In the study, the knowledge and skill literacy of patients with education of high school or technical secondary school was significantly higher than that of patients with junior middle school or below. Education can increase patient knowledge, which is inconsistent with another study [24]. High blood pressure skills can also be improved through education [25]. Hanafi et al.'s [26] studies have shown that health education not only can improve knowledge, but also can improve attitude and practice. Moreover, Toselli et al. [27] found that for North African women who moved to Italy, socioeconomic variables had a significant impact on obesity, with low education associated with an increased risk of obesity. It also suggests that low literacy can affect people's behavior. Results of multiple linear regression indicate that the educational level of patients can affect their level of medication literacy. With the gradual increasing of education level, the level of medication literacy of patients with hypertension has also increased, which were similar to the research in medication literacy of other populations [28]. The higher the level of education, the stronger and better the understanding of language and words of medical staff. However, this study indicates that the educational level is relatively low, especially for people with high blood pressure in junior high school or below. Effective measures should be taken to improve the medication literacy of the target population, paying particular attention to their knowledge and skills.

\section{Influence of level of income by year on medication literacy of patients with hypertension}

Different levels of annual income are also influencing factors affecting the level of medication literacy in hypertensive 
Table 3 Scores on medication literacy assessment scale of hypertensive patients of different characteristics

\begin{tabular}{|c|c|c|c|c|c|c|}
\hline Factors & Items & Knowledge literacy & Attitude literacy & Skill literacy & Practice literacy & $\begin{array}{l}\text { Scores on } \\
\text { medication } \\
\text { literacy }\end{array}$ \\
\hline \multirow[t]{3}{*}{ Age } & $18-44$ & $7.16 \pm 1.63$ & $5.17 \pm 1.35$ & $5.53 \pm 1.55$ & $9.25 \pm 1.70$ & $27.10 \pm 4.77$ \\
\hline & $45-59$ & $6.40 \pm 2.17^{\mathrm{a}}$ & $5.40 \pm 1.24$ & $4.73 \pm 2.10^{\mathrm{a}}$ & $8.33 \pm 1.93^{\mathrm{a}}$ & $24.87 \pm 5.02^{\mathrm{a}}$ \\
\hline & $\geq 60$ & $6.05 \pm 2.29^{\mathrm{a}}$ & $5.37 \pm 1.15$ & $4.19 \pm 2.20^{\mathrm{a}}$ & $8.38 \pm 1.97^{\mathrm{a}}$ & $24.01 \pm 5.11^{\mathrm{a}}$ \\
\hline$F$ value & & 6.539 & 0.878 & 11.300 & 5.430 & 9.510 \\
\hline$P$ value & & 0.002 & 0.416 & 0.000 & 0.000 & 0.000 \\
\hline \multirow[t]{2}{*}{ Gender } & Male & $6.66 \pm 2.06$ & $5.35 \pm 1.22$ & $4.77 \pm 2.02$ & $8.57 \pm 1.99$ & $25.35 \pm 4.92$ \\
\hline & Female & $5.81 \pm 2.30$ & $5.38 \pm 1.18$ & $4.19 \pm 2.26$ & $8.33 \pm 1.88$ & $23.71 \pm 5.25$ \\
\hline$T$ value & & 4.524 & 0.288 & 3.137 & 1.424 & 3.737 \\
\hline$P$ value & & 0.000 & 0.773 & 0.002 & 0.155 & 0.000 \\
\hline \multirow[t]{5}{*}{ Degree of education } & Primary or below & $5.21 \pm 2.20$ & $5.15 \pm 1.17$ & $3.95 \pm 2.30$ & $8.24 \pm 1.99$ & $22.55 \pm 4.99$ \\
\hline & Junior middle school & $5.92 \pm 2.20^{\mathrm{a}}$ & $5.44 \pm 1.21$ & $4.14 \pm 2.30$ & $8.14 \pm 1.88$ & $23.64 \pm 5.28$ \\
\hline & $\begin{array}{l}\text { Senior school or technical } \\
\text { secondary school }\end{array}$ & $6.49 \pm 1.97^{\mathrm{a}}$ & $5.36 \pm 1.14$ & $4.69 \pm 2.07^{\mathrm{a}}$ & $8.73 \pm 1.66$ & $25.27 \pm 4.19^{\mathrm{ab}}$ \\
\hline & Junior college & $7.31 \pm 1.66^{\mathrm{abc}}$ & $5.44 \pm 1.26$ & $5.10 \pm 1.64^{\mathrm{ab}}$ & $8.86 \pm 2.08$ & $26.70 \pm 4.49^{\mathrm{abc}}$ \\
\hline & College degree or above & $7.84 \pm 1.59^{\mathrm{abc}}$ & $5.55 \pm 1.23$ & $5.48 \pm 1.47^{\mathrm{abc}}$ & $8.79 \pm 2.11$ & $27.67 \pm 4.43^{\mathrm{abc}}$ \\
\hline$F$ value & & 28.482 & 1.943 & 9.733 & 3.270 & 20.234 \\
\hline$P$ value & & 0.000 & 0.102 & 0.000 & 0.012 & 0.000 \\
\hline \multirow[t]{5}{*}{ Annual income } & $\leq 10,000 /$ year & $5.45 \pm 2.53$ & $5.19 \pm 1.14$ & $4.11 \pm 2.22$ & $7.94 \pm 1.92$ & $22.68 \pm 4.79$ \\
\hline & $10,000-29,000 /$ year & $5.55 \pm 1.09$ & $5.33 \pm 1.09$ & $4.03 \pm 2.36$ & $8.13 \pm 2.05$ & $23.04 \pm 5.39$ \\
\hline & $30,000-49,000 /$ year & $6.57 \pm 2.01^{\mathrm{ab}}$ & $5.58 \pm 1.20$ & $4.54 \pm 2.20$ & $8.70 \pm 1.77^{\mathrm{a}}$ & $25.40 \pm 5.06^{\mathrm{ab}}$ \\
\hline & $50,000-99,000 /$ year & $6.80 \pm 1.98^{\mathrm{ab}}$ & $5.21 \pm 1.35$ & $5.18 \pm 1.85^{\mathrm{a}}$ & $8.64 \pm 2.22^{\mathrm{a}}$ & $25.83 \pm 5.09^{\mathrm{ab}}$ \\
\hline & $\geq 100,000 /$ year & $6.95 \pm 1.76^{\mathrm{ab}}$ & $5.38 \pm 1.19$ & $4.72 \pm 1.84$ & $8.77 \pm 8.46^{\mathrm{a}}$ & $25.82 \pm 4.36^{\mathrm{ab}}$ \\
\hline$F$ value & & 11.249 & 2.154 & 4.832 & 3.908 & 10.017 \\
\hline$P$ value & & 0.000 & 0.073 & 0.001 & 0.004 & 0.000 \\
\hline \multirow[t]{3}{*}{ Marital status } & Unmarried & $6.40 \pm 2.12$ & $5.05 \pm 1.09$ & $5.60 \pm 1.58$ & $9.28 \pm 1.71$ & $26.33 \pm 4.84$ \\
\hline & Married & $6.33 \pm 2.18$ & $5.34 \pm 1.22$ & $4.53 \pm 2.14$ & $8.44 \pm 1.98$ & $24.65 \pm 5.16$ \\
\hline & Divorced or widowed & $5.78 \pm 2.46$ & $5.60 \pm 1.05$ & $4.08 \pm 2.25$ & $8.51 \pm 1.65$ & $23.98 \pm 4.91$ \\
\hline$F$ value & & 1.441 & 1.431 & 2.355 & 0.926 & 0.962 \\
\hline$P$ value & & 0.238 & 0.240 & 0.096 & 0.397 & 0.383 \\
\hline \multirow[t]{3}{*}{ Occupational status } & On-the-job & $6.31 \pm 2.24$ & $5.38 \pm 1.22$ & $4.62 \pm 2.17$ & $8.52 \pm 1.91$ & $24.83 \pm 5.16$ \\
\hline & Retired & $6.63 \pm 2.05$ & $5.48 \pm 1.09$ & $4.41 \pm 2.08$ & $8.46 \pm 2.10$ & $24.97 \pm 4.90$ \\
\hline & Jobless & $4.89 \pm 1.93^{\mathrm{ab}}$ & $4.78 \pm 1.25^{\mathrm{ab}}$ & $3.76 \pm 2.03^{\mathrm{a}}$ & $7.86 \pm 1.64$ & $21.29 \pm 4.51^{\mathrm{ab}}$ \\
\hline$F$ value & & 9.322 & 5.236 & 2.915 & 2.032 & 8.883 \\
\hline$P$ value & & 0.000 & 0.006 & 0.055 & 0.132 & 0.000 \\
\hline \multirow[t]{2}{*}{ Residence } & Urban & $6.68 \pm 2.03$ & $5.46 \pm 1.20$ & $4.68 \pm 2.01$ & $8.54 \pm 1.96$ & $25.37 \pm 4.78$ \\
\hline & Rural areas & $5.75 \pm 2.33$ & $5.22 \pm 1.19$ & $4.27 \pm 2.31$ & $8.35 \pm 1.92$ & $23.60 \pm 5.41$ \\
\hline$T$ value & & 4.910 & 2.323 & 2.201 & 1.140 & 4.022 \\
\hline$P$ value & & 0.000 & 0.021 & 0.028 & 0.255 & 0.000 \\
\hline \multirow[t]{5}{*}{ Medical insurance type } & $\begin{array}{l}\text { Without medical insur- } \\
\text { ance }\end{array}$ & $3.29 \pm 1.70$ & $4.25 \pm 0.85$ & $1.86 \pm 2.34$ & $7.39 \pm 2.31$ & $16.79 \pm 4.90$ \\
\hline & $\begin{array}{l}\text { New rural cooperative } \\
\text { medical insurance }\end{array}$ & $5.62 \pm 2.33^{\mathrm{a}}$ & $5.29 \pm 1.25^{\mathrm{a}}$ & $4.43 \pm 2.33^{\mathrm{a}}$ & $8.28 \pm 1.92$ & $23.63 \pm 5.46^{\mathrm{a}}$ \\
\hline & $\begin{array}{l}\text { Medical insurance for } \\
\text { urban workers }\end{array}$ & $7.13 \pm 1.85^{\mathrm{a}}$ & $5.45 \pm 1.20^{\mathrm{a}}$ & $4.92 \pm 1.82^{\mathrm{a}}$ & $8.55 \pm 2.08$ & $26.05 \pm 4.59^{\mathrm{a}}$ \\
\hline & $\begin{array}{l}\text { Medical insurance for } \\
\text { urban residents }\end{array}$ & $5.81 \pm 1.94^{\mathrm{a}}$ & $5.31 \pm 1.10^{\mathrm{a}}$ & $3.87 \pm 2.22^{\mathrm{a}}$ & $8.70 \pm 1.62$ & $23.70 \pm 4.56^{\mathrm{a}}$ \\
\hline & Others & $6.73 \pm 2.34^{\mathrm{a}}$ & $5.75 \pm 0.86^{\mathrm{a}}$ & $4.33 \pm 1.88^{\mathrm{a}}$ & $8.65 \pm 1.71$ & $25.47 \pm 4.00^{\mathrm{a}}$ \\
\hline$F$ value & & 19.779 & 2.423 & 6.972 & 1.448 & 12.119 \\
\hline$P$ value & & 0.000 & 0.047 & 0.000 & 0.217 & 0.000 \\
\hline
\end{tabular}


Table 3 (continued)

\begin{tabular}{|c|c|c|c|c|c|c|}
\hline Factors & Items & Knowledge literacy & Attitude literacy & Skill literacy & Practice literacy & $\begin{array}{l}\text { Scores on } \\
\text { medication } \\
\text { literacy }\end{array}$ \\
\hline \multirow[t]{4}{*}{ History of hypertension } & $<3$ year & $6.07 \pm 2.24$ & $5.20 \pm 1.25$ & $4.61 \pm 2.24$ & $8.67 \pm 1.81$ & $24.55 \pm 5.30$ \\
\hline & $3-4$ year & $5.84 \pm 2.11$ & $5.23 \pm 1.21$ & $4.84 \pm 2.14$ & $8.38 \pm 1.87$ & $24.29 \pm 5.07$ \\
\hline & 5-9 year & $6.47 \pm 2.16$ & $5.34 \pm 1.22$ & $4.37 \pm 2.27$ & $8.40 \pm 2.04$ & $24.57 \pm 5.23$ \\
\hline & $\geq 10$ year & $6.45 \pm 2.26$ & $5.52 \pm 1.14$ & $4.41 \pm 2.01$ & $8.44 \pm 1.98$ & $24.82 \pm 5.02$ \\
\hline$F$ value & & 2.243 & 2.291 & 1.165 & 0.497 & 0.24 \\
\hline$P$ value & & 0.082 & 0.077 & 0.322 & 0.684 & 0.868 \\
\hline \multirow{2}{*}{$\begin{array}{l}\text { Family history of hyper- } \\
\text { tension }\end{array}$} & Yes & $6.57 \pm 2.19$ & $5.36 \pm 1.24$ & $4.67 \pm 2.09$ & $8.44 \pm 2.04$ & $25.04 \pm 5.12$ \\
\hline & No & $5.76 \pm 2.16$ & $5.36 \pm 1.14$ & $4.22 \pm 2.23$ & $8.50 \pm 1.77$ & $23.84 \pm 5.07$ \\
\hline$T$ value & & 4.142 & 0.043 & 2.344 & 0.345 & 2.611 \\
\hline$P$ value & & 0.000 & 0.966 & 0.019 & 0.730 & 0.009 \\
\hline \multirow{2}{*}{$\begin{array}{l}\text { Hypertension complica- } \\
\text { tion }\end{array}$} & Yes & $6.10 \pm 2.39$ & $5.35 \pm 1.11$ & $4.27 \pm 2.32$ & $8.35 \pm 2.20$ & $24.07 \pm 5.68$ \\
\hline & No & $6.35 \pm 2.14$ & $5.37 \pm 1.23$ & $4.60 \pm 2.08$ & $8.50 \pm 1.84$ & $24.82 \pm 4.90$ \\
\hline$T$ value & & 1.156 & 0.144 & 1.597 & 0.827 & 1.516 \\
\hline$P$ value & & 0.248 & 0.885 & 0.111 & 0.409 & 0.130 \\
\hline \multirow{3}{*}{$\begin{array}{l}\text { The number of antihyper- } \\
\text { tensive medication being } \\
\text { taken }\end{array}$} & 1 kind & $6.43 \pm 2.10$ & $5.29 \pm 1.18$ & $4.63 \pm 2.13$ & $8.45 \pm 1.95$ & $24.80 \pm 4.85$ \\
\hline & $2-3$ kinds & $6.17 \pm 2.31$ & $5.47 \pm 1.22$ & $4.31 \pm 2.20$ & $8.54 \pm 1.93$ & $24.49 \pm 5.57$ \\
\hline & 4 kinds or above & $5.05 \pm 2.59^{\mathrm{a}}$ & $5.53 \pm 1.22$ & $4.32 \pm 1.94$ & $7.95 \pm 1.96$ & $22.85 \pm 5.15$ \\
\hline$F$ value & & 4.485 & 1.616 & 1.389 & 0.883 & 1.578 \\
\hline$P$ value & & 0.012 & 0.200 & 0.250 & 0.414 & 0.207 \\
\hline \multirow{4}{*}{$\begin{array}{l}\text { The number of people } \\
\text { who live together }\end{array}$} & 1 or below & $6.33 \pm 2.41$ & $5.14 \pm 1.12$ & $3.79 \pm 2.25$ & $8.75 \pm 1.63$ & $24.01 \pm 5.50$ \\
\hline & $2-4$ & $6.44 \pm 2.21$ & $5.43 \pm 1.22$ & $4.61 \pm 2.13$ & $8.59 \pm 1.92$ & $25.07 \pm 5.16$ \\
\hline & $5-7$ & $6.02 \pm 2.07$ & $5.24 \pm 1.14$ & $4.43 \pm 2.21$ & $8.27 \pm 2.05$ & $23.96 \pm 4.96$ \\
\hline & 8 or above & $5.61 \pm 2.54$ & $5.34 \pm 1.27$ & $4.25 \pm 1.96$ & $7.61 \pm 1.72^{\mathrm{ab}}$ & $22.80 \pm 4.58$ \\
\hline$F$ value & & 2.151 & 1.166 & 1.364 & 2.916 & 2.987 \\
\hline$P$ value & & 0.093 & 0.322 & 0.253 & 0.034 & 0.031 \\
\hline
\end{tabular}

${ }^{\text {a }}$ Compared with the first layer, $P<0.05$

${ }^{\mathrm{b}}$ Compared with the second layer, $P<0.05$

${ }^{\mathrm{c}}$ Compared with the third layer, $P<0.05$

patients. With the increase of annual income, the level of medication literacy of the patients will be improved. It was different in dimensions of knowledge, skills and practical behavior literacy between those with annual income of less than 30,000 yuan and of more than 30,000 yuan $(P<0.05)$, which suggested that hypertensive patients with higher annual incomes were more likely to pay more attention to promoting health level and they value the health education of medical staff than those with lower annual incomes. Socioeconomic factors have been shown to affect health through matter [20]. Maybe people with high salaries are willing to spend a lot of money on health care and health promotion. In this study, 200 patients with an annual income of less than 30,000 yuan, among which $76 \%$ have a junior middle school education or below, indicating that patients with a low annual income generally have a low educational level.
Nonetheless, hypertension patients with lower education and better cognitive status often benefit the most from intervention [30]. Therefore, hypertensive patients with lower annual income are also the focus group for improving medication literacy. However, differences in annual income did not significantly affect hypertension patients' attitudes to disease and medication management. Patients' attitudes may be related to symptoms of high blood pressure, their level of attention, and their use of medications, just like a Belgian study [31]. The influence of economic income on the attitude dimension of medication literacy may not be significant.

\section{Influence of occupational status on medication literacy of patients with hypertension}

The results showed that the knowledge level of unemployed patients was lower than that of retired and occupied patients, 
Table 4 Variables assignment of analysis on influencing factors of medication literacy of hypertensive patients

\begin{tabular}{|c|c|}
\hline Variables & Assignment \\
\hline Gender & Male $=1 ;$ female $=2$ \\
\hline Age group & $18-44$ years old $=1 ; 45-60$ years old $=2 ; \geq 60$ years old $=3$ \\
\hline Marital status & $\begin{array}{l}\text { Referring to "unmarried" as dumb variable: } \mathrm{M} 1=\text { married }(1,0), \mathrm{M} 2=\text { divorced or widowed } \\
(0,1)\end{array}$ \\
\hline Degree of education & $\begin{array}{l}\text { Primary level and below }=1 \text {; Junior middle school }=2 \text {; Senior school or technical secondary } \\
\text { school }=3 \text {; Junior College }=4 \text {; College degree or above }=5\end{array}$ \\
\hline Occupational status & Referring to the retired as dumb variable: $\mathrm{P} 1=$ on-the-job $(1,0), \mathrm{P} 2=$ jobless $(0,1)$ \\
\hline Annual income & $\begin{array}{l}\leq 10,000 / \text { year }=1 ; 10,000-29,000 / \text { year }=2 ; 30,000-49,000 / \text { year }=3 ; 50,000-99,000 / \text { year }=4 \\
\geq 100,000 / \text { year }=5\end{array}$ \\
\hline Residence & Urban area $=1 ;$ Rural area $=2$ \\
\hline The number of people who lived together & 1 or below $=1 ; 2-4$ persons $=2 ; 5-7$ persons $=3 ; 8$ or above $=4$ \\
\hline Medical insurance type & $\begin{array}{l}\text { Referring to "without medical insurance" as dumb variable: } \mathrm{I} 1=\text { Medical insurance for urban } \\
\text { workers }(1,0,0,0), \mathrm{I} 2=\text { Medical insurance for urban residents }(0,1,0,0), \mathrm{I} 3=\text { New rural } \\
\text { cooperative medical insurance }(0,0,1,0), \mathrm{I} 4=\text { others }(0,0,0,1)\end{array}$ \\
\hline History of hypertension & $<3$ years $=1 ; 3-4$ years $=2 ; 5-9$ years $=3 ; \geq 10$ years $=4$ \\
\hline Family history of hypertension & Yes $=1 ;$ no $=2$ \\
\hline Hypertension complication & Yes $=1 ;$ no $=2$ \\
\hline Kinds of antihypertensive medication being taken & 1 or below $=1 ; 2-3$ kinds $=2 ; 4$ or above $=3$ \\
\hline
\end{tabular}

Table 5 Results of multiple linear regression analysis on each dimension of medication literacy of hypertensive patients

Model summary

\begin{tabular}{|c|c|c|c|c|c|c|}
\hline \multirow{3}{*}{$\begin{array}{l}\text { Model } \\
1\end{array}$} & \multirow{3}{*}{$\begin{array}{l}\mathrm{R} \\
0.349^{\mathrm{a}}\end{array}$} & \multirow{3}{*}{$\begin{array}{l}\text { R2 } \\
0.122 \\
\text { B }\end{array}$} & \multirow{2}{*}{\multicolumn{2}{|c|}{$\begin{array}{l}\text { Adjusted R2 } \\
0.117\end{array}$}} & \multirow{2}{*}{\multicolumn{2}{|c|}{$\begin{array}{l}\text { Error of standard estimate } \\
5.278\end{array}$}} \\
\hline & & & & & & \\
\hline & & & SE & Beta & $T$ & $P$ \\
\hline \multicolumn{2}{|l|}{ (constant) } & 15.194 & 2.420 & & 6.279 & 0.000 \\
\hline \multicolumn{2}{|l|}{ Degree of education } & 0.941 & 0.188 & 0.256 & 5.006 & 0.000 \\
\hline \multicolumn{2}{|l|}{ Annual income } & 0.488 & 0.170 & 0.128 & 2.868 & 0.004 \\
\hline \multicolumn{2}{|l|}{ P1 on-the-job } & 0.115 & 0.504 & 0.010 & 0.229 & 0.819 \\
\hline \multicolumn{2}{|l|}{$\mathrm{P} 2$ jobless } & -2.429 & 0.911 & -0.121 & -2.667 & 0.008 \\
\hline \multicolumn{2}{|c|}{ I1 Medical insurance for urban workers } & 7.562 & 1.814 & 0.728 & 4.169 & 0.000 \\
\hline \multicolumn{2}{|c|}{ I2 Medical insurance for urban residents } & 6.557 & 1.848 & 0.468 & 3.549 & 0.000 \\
\hline \multicolumn{2}{|c|}{ I3 New rural cooperative medical insurance } & 7.212 & 1.806 & 0.684 & 3.993 & 0.000 \\
\hline \multicolumn{2}{|l|}{ I4 others } & 7.581 & 2.155 & 0.243 & 3.518 & 0.000 \\
\hline
\end{tabular}

${ }^{\text {a} P r e d i c t i v e ~ v a r i a b l e s: ~(c o n s t a n t), ~ e d u c a t i o n ~ l e v e l, ~ o c c u p a t i o n a l ~ s t a t u s, ~ a n d ~ m e d i c a l ~ i n s u r a n c e ~}$

including the knowledge of disease and medication, attitudes towards disease and medication administration, and skills for medication administration. Results of multiple linear regression also suggest that occupational status is one of the influencing factors of medication literacy of hypertensive patients. Among all the unemployed residents, 92.1\% have a junior high school education or below, and $60.5 \%$ have an education above the age of sixty, which indicates that attention should be paid to the improvement of medical literacy of the unemployed. There is also a study abroad that shows that people who are employed have a higher level of education [32]. In addition, Eikemo et al. [33] found that among Greek-born immigrant groups, women are more likely to develop non-communicable diseases, which may be due to occupational factors. Thus, the importance of occupational factors can be seen.

\section{Influence of type of medical insurance on medication literacy of patients with hypertension}

Among the hypertensive patients with different medical insurance types, the knowledge level of hypertensive patients with urban workers' medical insurance was the highest, 
followed by the new rural cooperative medical insurance and urban residents' medical insurance, and the knowledge level of hypertensive patients without medical insurance was the lowest. The results of multiple linear regression analysis also show that the type of medical insurance is one of the factors affecting the knowledge level of hypertension patients, which may be because patients with urban residents' medical insurance have better economic conditions [34-36]. Furthermore, due to better medical reimbursement in such two kinds of medical insurance, patients may take less concern of medical expenses and focus mainly on their disease. Therefore, the medication literacy of hypertensive patients without medical insurance should be better promoted.

\section{Recommendations for improving the level of medication literacy in hypertensive patients}

Carry out comprehensive screening of medication literacy for hypertensive patients, and determine the key intervention population. First of all, it is necessary to use medication literacy assessment tools for screening and evaluating medication literacy of hypertensive patients to identify the urgency and necessity of medication literacy promotion strategies. At the same time, specific measures should be taken to identify individual differences to better improve the safety of drug use. In addition, attention should be paid to the low education, low income, unemployment, no insurance, to improve their medication literacy. Health education is mainly to improve the quality of medication literacy in patients with hypertension through effective intervention measures by health service personnel, which is very important. Therefore, it is necessary to carry out systematic and professional training for health service personnel, so as to make health education more comprehensive and conducive to patients' acceptance. Meanwhile, we need government oversight and policies to help primary care providers provide sustainable self-medication guidance to patients.

\section{Limitations}

Our study has some limitations. Self-report bias exists in this study. In addition, selection bias may exist in patients with hypertension as most of them are elderly. In addition, the analysis of influencing factors related to medication literacy may be incomplete, and cross-sectional study designs may not be able to determine the causal relationship between the variables of interest. The results may not apply to other populations.

\section{Conclusion}

Adequate medication literacy is helpful for the control of blood pressure, but medication literacy of hypertensive patients is generally low. Therefore, medication literacy of hypertensive patients needs to be improved. Attention should be paid to the low education, low income, unemployment, no insurance, to improve their medication literacy. Health education is an important measure to ensure the safe selfmedication of hypertensive patients. Besides, screening patients in need of help for intervention, systematic training of health service personnel and comprehensive mobilization of medical resources can provide a way to improve the level of medication literacy of hypertensive patients.

Acknowledgements The authors thank Dr. Zhong's team at Third Xiangya Hospital of Central South University in Changsha, China for their contributions to this study.

\section{Compliance with ethical standards}

Conflict of interest The authors declare that they have no competing interests (political, personal, financial, religious, ideological, academic, or any other) in relation to this manuscript.

Statement of human and animal rights This study has been approved from Ethics and Research committee of Third Xiangya Hospital of Central South University.

Informed consent Informed consent was obtained from patients before enrollment. The Ethics and Research Committee of Third Xiangya Hospital of Central South University approved all procedures.

Open Access This article is distributed under the terms of the Creative Commons Attribution 4.0 International License (http://creativeco mmons.org/licenses/by/4.0/), which permits unrestricted use, distribution, and reproduction in any medium, provided you give appropriate credit to the original author(s) and the source, provide a link to the Creative Commons license, and indicate if changes were made.

\section{References}

1. Weiwei C, Runlin G, Lisheng L (2017) Summary of China cardiovascular diseases report 2016. Chin Circ J 32(06):521-530

2. Ma L, Wu Y, Wang W, Chen W (2018) Report of cardiovascular diseases in China 2017. Chin J Cardiovasc Sci 23(1):3-6. https:// doi.org/10.3969/j.issn.1007-5410.2018.01.002

3. Bosworth HB, Olsen MK, Grubber JM, Neary AM, Orr MM, Powers BJ, Li Y (2009) Two self-management interventions to improve hypertension control: a randomized trial. Ann Internal Med 151(10):687-695. https://doi.org/10.7326/0003-4819-15110-200911170-00148

4. Mendis S, Davis S, Norrving B (2015) Organizational update: the world health organization global status report on non-communicable diseases 2014; one more landmark step in the combat against stroke and vascular disease. Stroke 46(5):e121. https://doi. org/10.1161/STROKEAHA.115.008097 
5. Castilla-Guerra L, Fernández-Moreno MC, Alvarez-Suero J (2009) Secondary stroke prevention in the elderly: new evidence in hypertension and hyperlipidemia. Eur J Internal Med 20(6):586-590. https://doi.org/10.1016/j.ejim.2009.06.005

6. Saqlain M, Riaz A, Malik MN, Khan S, Ahmed A, Kamran S, Ali $\mathrm{H}$ (2019) Medication adherence and its association with health literacy and performance in activities of daily livings among elderly hypertensive patients in Islamabad, Pakistan. [Journal Article]. Medicina (Kaunas). https://doi.org/10.3390/medicina55050163

7. Feng Z, Wright B, Mor V (2012) Sharp rise in medicare enrollees being held in hospitals for observation raises concerns about causes and consequences. Health Aff 31(6):1251. https://doi. org/10.1377/hlthaff.2012.0129

8. Wodchis WP (2016) Analysing high-cost users of healthcare in Canada. Pharmacoecon Outcomes News 745(1):9. https://doi. org/10.1007/s40274-016-2750-9

9. Tibi-Levy Y, Pouvourville GD, Westerloppe J, Bamberger M (2008) The cost of treating high blood pressure in general practice in France. Eur J Health Econ Hepac Health Econ Prevent Care 9(3):229-236. https://doi.org/10.1007/s10198-007-0065-2

10. Jufang S, Huiyun S (2010) Some views about the high cost of medical care in China. [Journal Article; Research Support, NonUS Govt]. Southeast Asian J Trop Med Public Health 41(1):240242. https://doi.org/10.1111/j.1467-9566.2009.01213.x

11. COR China (2012) Guidelines for the prevention and treatment of hypertension in China (revised in 2010). Chin J Pract Rural Doctors 19(12):1-15. https://doi.org/10.3969/j. issn.1672-7185.2012.10.001

12. Lor M, Koleck TA, Bakken S, Yoon S, Dunn NA (2019) Correction to: Association between health literacy and medication adherence among hispanics with hypertension [Published Erratum]. J Racial Ethn Health Disparities. https://doi.org/10.1007/s4061 5-019-00588-7

13. Bhuyan SS, Shiyanbola O, Kedia S, Chandak A, Wang Y, Isehunwa OO, Ahn SN (2016) Does cost-related medication nonadherence among cardiovascular disease patients vary by gender? Evidence from a Nationally Representative Sample. Womens Health Issues 27(1):108-115. https://doi.org/10.1016/j. whi.2016.10.004

14. Ritchey M, Chang A, Powers C, Loustalot F, Schieb L, Ketcham M, Hong Y (2016) Vital signs: disparities in antihypertensive medication nonadherence among medicare Part D beneficiaries-United States, 2014. [Journal Article]. MMWR Morb Mortal Wkly Rep 65(36):967-976

15. Lau R, Stewart K, Mcnamara KP, Jackson SL, Hughes JD, Peterson GM, Hsueh A (2010) Evaluation of a community pharmacybased intervention for improving patient adherence to antihypertensives: a randomised controlled trial. BMC Health Serv Res 10(1):1-7. https://doi.org/10.1186/1472-6963-10-34

16. Crowley MJ, Zullig LL, Shah BR, Shaw RJ, Lindquist JH, Peterson ED, Bosworth HB (2015) Medication non-adherence after myocardial infarction: an exploration of modifying factors [Journal Article; Randomized Controlled Trial; Research Support, Non-US Govt; Research Support, US Govt, Non-PHS]. J Gen Intern Med 30(1):83-90. https://doi.org/10.1007/s1160 6-014-3072-x

17. Rabbia F, Fulcheri C, Monaco SD, Covella M, Perlo E, Pappaccogli M, Veglio F (2016) Adherence to antihypertensive therapy and therapeutic dosage of antihypertensive drugs. High Blood Pressure Cardiovasc Prevent 23(4):341-345. https://doi. org/10.1007/s40292-016-0158-Z

18. Yeh YC, Lin HW, Chang EH, Huang YM, Chen YC, Wang CY, Ko Y (2017) Development and validation of a Chinese medication literacy measure. [Journal Article; Validation Studies]. Health Expect 20(6):1296-1301. https://doi.org/10.1111/hex.12569
19. Kripalani S, Henderson LE, Chiu EY, Robertson R, Kolm P, Jacobson TA (2010) Predictors of medication self-management skill in a low-literacy population. J Gen Internal Med 21(8):852856. https://doi.org/10.1111/j.1525-1497.2006.00536.x

20. Pouliot A, Vaillancourt R, Stacey D, Suter P (2018) Defining and identifying concepts of medication literacy: an international perspective. [Journal Article; Research Support, Non-US Govt]. Res Social Adm Pharm 14(9):797-804. https://doi.org/10.1016/j.sapha rm.2017.11.005

21. Raynor DK (2008) Medication literacy is a 2-way street. [Comment; Editorial]. Mayo Clin Proc 83(5):520-522. https://doi. org/10.4065/83.5.520

22. Newman V (2018) Structured patient education utilizing the medication oral agent teaching tool and medication adherence in oncology patients prescribed oral chemotherapy. https://stti.confe x.com/stti/congrs18/webprogram/Paper91579.html

23. Lin AH, Kendrick JG, Wilcox PG, Quon BS (2017) Patient knowledge and pulmonary medication adherence in adult patients with cystic fibrosis. [Journal Article]. Patient Prefer Adherence 11:691-698. https://doi.org/10.2147/PPA.S129088

24. Adeomi AA, Adeoye OA, Asekun-Olarinmoye EO, Abodunrin OL, Olugbenga-Bello AI, Sabageh AO (2014) Evaluation of the effectiveness of peer education in improving HIV knowledge, attitude, and sexual behaviours among in-school adolescents in Osun State. Nigeria Aids Res Treat 14:131756. https://doi. org/10.1155/2014/131756

25. Block L, Flynn SJ, Cooper LA, Lentz C, Hull T, Dietz KB, Boonyasai RT (2018) Promoting sustainability in quality improvement: an evaluation of a web-based continuing education program in blood pressure measurement. BMC Fam Pract 19(1):13. https:// doi.org/10.1186/s12875-017-0682-5

26. Hanafi MI, Hamid Shalaby SA, Falatah N, El-Ammari H (2014) Impact of health education on knowledge of, attitude to and practice of breastfeeding among women attending primary health care centres in Almadinah Almunawwarah, Kingdom of Saudi Arabia: controlled pre-post study. J Taibah Univ Med Sci 9(3):187-193. https://doi.org/10.1016/j.jtumed.2013.11.011

27. Toselli S, Rinaldo N, Gualdi-Russo E (2019) Length of residence and obesity risk among North African immigrant women in Italy. Econ Hum Biol. https://doi.org/10.1016/j.ehb.2019.03.008

28. Zhong Z, Feng Z, Guo Y, Luo A (2016) Medication literacy in a cohort of Chinese patients discharged with acute coronary syndrome. Int J Environ Res Public Health 13(7):720. https://doi. org/10.3390/ijerph13070720

29. Arpey NC, Gaglioti AH, Rosenbaum ME (2017) How socioeconomic status affects patient perceptions of health care: a qualitative study. J Prim Care Community Health 8(3):169-175. https:// doi.org/10.1177/2150131917697439

30. Smeulders ES, van Haastregt JC, Ambergen T, Stoffers HE, Janssen-Boyne JJ, Uszko-Lencer NH, Kempen GI (2010) Heart failure patients with a lower educational level and better cognitive status benefit most from a self-management group programme. [Journal Article; Randomized Controlled Trial; Research Support, Non-US Govt]. Patient Educ Couns 81(2):214-221. https://doi. org/10.1016/j.pec.2010.01.003

31. Tchicaya A, Lorentz N, Demarest S (2017) Income-related inequality in smoking cessation among adult patients with cardiovascular disease: a 5-year follow-up of an angiography intervention in Luxembourg. [Journal Article; Research Support, Non-US Govt]. BMC Cardiovasc Disord 17(1):107. https://doi.org/10.1186/s1287 2-017-0541-2

32. Serinken M, Turkcuer I, Karcioglu O, Akkaya S, Uyanik E (2011) Domestic accidents involving women and first aid knowledge. [English Abstract; Journal Article]. Ulus Travma Acil Cerrahi Derg 17(5):445-449. https://doi.org/10.5505/tjtes.2011.55649 
33. Eikemo TA, Gkiouleka A, Rapp C, Utvei SS, Huijts T, Stathopoulou T (2018) Non-communicable diseases in Greece: inequality, gender and migration. Eur J Public Health 28(suppl 5):38-47. https://doi.org/10.1093/eurpub/cky219

34. Liu H, Zhao Z (2014) Does health insurance matter? Evid China's Urban Resident Basic Med Insurance 42(4):1007-1020. https:// doi.org/10.1016/j.jce.2014.02.003

35. Pan J, Tian S, Zhou Q, Han W (2016) Benefit distribution of social health insurance: evidence from china's urban resident basic medical insurance. Health Pol Plan 31(7):853. https://doi.org/10.1093/ heapol/czv141
36. Zhu K, Zhang L, Yuan S, Zhang X, Zhang Z (2017) Health financing and integration of urban and rural residents' basic medical insurance systems in China. Int J Equity Health 16(1):194. https ://doi.org/10.1186/s12939-017-0690-z

Publisher's Note Springer Nature remains neutral with regard to jurisdictional claims in published maps and institutional affiliations. 